\title{
A Strategic Approach in Handling Information Retrieval Course for Attaining Course Outcomes - A Case Study
}

\author{
A.Sheik Abdullah ${ }^{1}$, P.Karthikeyan ${ }^{2}$ S.Selvakumar ${ }^{3}$ R.Parkavi $^{4}$ \\ ${ }^{1,2,4}$ Department of Information Technology, Thiagarajar College of Engineering, Madurai. \\ ${ }^{3}$ Department of CSE, GKM College of Engineering and Technology, Chennai. \\ 1 asait@tce.edu \\ ${ }^{2}$ karthikit@tce.edu \\ 3 sselvakumar@yahoo.com \\ ${ }^{4}$ rpit@tce.edu
}

\begin{abstract}
:
Background:

The major challenge in engineering education is to educate and train the student's community with pedagogical practices in order to determine the notable skills to solve more complex and fragile structured problems. Innovative pedagogical practices make the students to adhere to the complex formulations of the corresponding domain and its applications. The realm of good understanding of knowledge and its deliverables can be ascertained through pedagogical practices with a focus on learner-centric activities in the classroom teaching.
\end{abstract}

The actual target in teaching learning process is to make all the students to have a good exploration on the domain knowledge with success ratio. The learner success is considered to be the core metric with which we can judge the success of learner-centric activities with creativity and quality processes. Confirming the process in which the learners are engaged with the key ideas of the course to be taught makes the students to have practical implementations in Teaching-Learning process.

\section{Objective:}

This research work focus on the assessment and evaluation of learner-centric techniques for outcome based education upon statistical evaluation. Students of third year (VI Semester) of two consecutive batches have been analyzed for the course on Information Retrieval (14ITPS0). Two set of batches 2015-19 and 2016-20 have been considered for the assessment and analysis of Active Learning Strategies (ALS). The incorporation has been processed using the strategic approach based on daily, weekly and monthly assessments focusing on student learning criteria and their responding behaviors for 2016-20 batch. Each paradigm has been measured corresponding to the course outcomes at each level. Significant statistical analysis has been made for validating the process behind the teaching learning process.

\section{Real time case study:}

Considering the batch 2015-19 summary assignments, presentations has been used for the evaluation and assessment of interim assignments. The observed response from the students went well among the student's community. All the students have been registered for the course and they too have completed the same. But, the time and success ratio in learning mechanism varied from student to student upon completion of the course.

Considering the batch 2016-20 active learning strategies such as Quiz by Kahoot!, Flipped classroom activity and MOOCs course has been incorporated. Also, for MOOC'S online courses a set of two courses has been identified relevant to the subject of study such as Text Retrieval and Search engines \& Text mining and Analytics. For the Research problem identification the students are allowed to choose the domain specific topics for the course on information retrieval. In this process the time and success ratio has also been observed it also varied from one student to another.

Keywords: Education Technology, Course Outcomes, Target Measures, Interim Assessment, Learner-centric activities, Outcome-based Education.

\section{Corresponding Author}

A.Sheik Abdullah

Assistant Professor

Department of Information Technology

Thiagarajar College of Engineering, Madurai.

Email: asait@tce.edu

\section{Introduction}

The domain of educational technology is moving its wings from teacher-centric to learner centric activities in order to make the students to have an effective content delivery and understanding of each subject due course of study. The impact of learning among the students community must make them to have an adaptable environment in the teaching learning process. This will make changes in the process behind the student learning schemes. Accessing and evaluating the student deliverables must be made accordingly to that of the student's acceptable patterns which then surely reflects some fruitful course outcomes.

Learning by doing some activities will surely make the student's environment more flexible and adaptable with 
specific constraints. These constraints will vary accordingly from student to student learning process and their learning environment. Activities concerning to ICT in OBE with a keen focus on Active Learning Strategies (ALS) will significantly have an impact in the teaching learning process.

This research paper deals with the applicability of ALS for the course on Information retrieval with the motto of making significant change in the teaching learning process. Strategies focusing on quiz, flipped classroom, online learning along with research-based exploration have been considered for the assessment and evaluation of course outcomes with the incorporation of ICT in action.

\section{Literature Review}

The work by the authors (Sheik Abdullah, et.al. 2018) proposed a target fixing scheme for the attainment of course outcomes. The target fixing has been made accordingly in two ways with upper and lower control limits. The proposed target fixing scheme by the authors made a significant improvement in the attainment of course outcomes for the course on information systems.

\section{Technical Details and Implementation}

Self-learning is considered to be an important part in student learning process (Parkavi et.al. 2018). The intention of self-learning varies significantly from student to student based on their ability and learning criteria (Baker et.al. 2012). In this case study we have considered two batches for measuring the effectiveness of learning with the proposed strategic approach. The course on information retrieval consists of 5 modules such as:

1. Data modeling

2. Querying

3. Text operations

4. Web search

5. Applications

The following Figure 1 depicts the course contents and its structure in the form of Cmap.

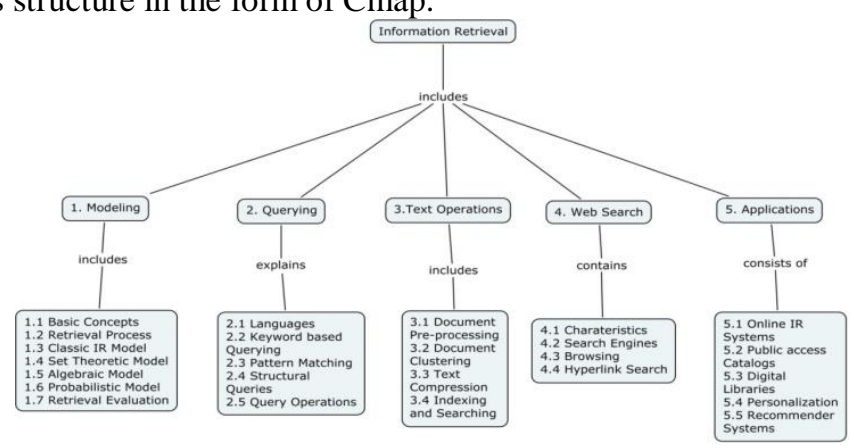

Figure 1. Information Retrieval course contents

The following are the course outcomes in which the student will acquire upon completion of the course. Upon completion of the course the students will be able to:
- Use information retrieval modeling techniques for Corpus documents

- Apply query processing techniques to locate relevant information from the large collection of data

- Apply information retrieval techniques for textual data

- Evaluate different information retrieval systems for web search tasks

- Develop simple information retrieval system for applications like personalization and recommender systems, search engines, etc

The assessment of course evaluation lies at remember level of about $20 \%$, understand level of about $20 \%$, apply level $50 \%$ and analyze at $10 \%$. The level of each module has to be mapped in accordance with the understanding level of the students (Ouafae et.al. 2019). The contents have been formulated in such a way that it coincides with the understanding of each and every student (Gloria et.al. 2013). The Active Learning Strategies (ALS) included is:

1. Quiz by Kahoot! (Daily Assessment)

2. Flipped classroom (Weekly Assessment)

3. MOOCs online courses (Monthly Assessment)

Apart from this the student with more adverse exposure will be given an opportunity to formulate research proposals as an activity for making them to focus on research-based applications (Duarte et al., 2020). The following Figure 2 provides the daily evaluation by using ICT tool (Kahoot!). The students with correct answers will be ranked and the same will be displayed through podium. This mechanism makes the students to participate enthusiastically with interest and understanding of learning the concepts (Ounjit, et.al. 2011). The attainment is evaluated with the following calculation process:

CO, PO, PSO Attainment Calculation Process:

Use historical data for fixing the targets

Expected Proficiency (EP)

Expected Level of Attainment (ELA)

\section{Target Fixing}

- Count the number of Students Grade wise

- Calculate Average of two batches for each Grade

- Find cumulative \% of Average

- Set EP, in which the cumulative Average crosses $50 \%$

- $\quad$ Set ELA with $30 \%$ increase (use nearest 10 s) 


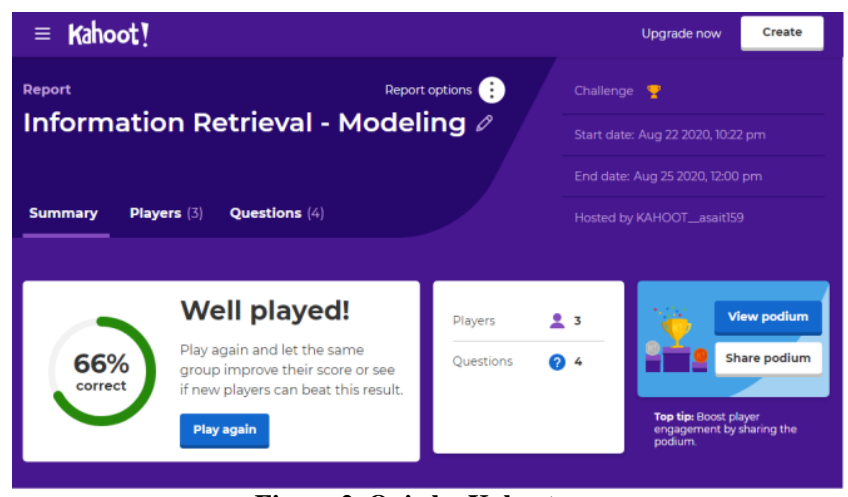

Figure 2. Quiz by Kahoot

The weekly assessment is made through another ICT mechanism with a keen focus on flipped classroom activity (Rhode Island, 2016). This is pedagogical approaches which express the instructions from group learning to an individual learning environment (Parkavi, et.al. 2017). This situation enables the students to have a creative learning atmosphere where they can apply the concepts related to the flipped classroom activity (Friess, et.al. 2020). The modules has been segregated into three components one focusing on Quiz, another on flipped classroom, and finally on MOOCs and preparation of research report. The following Table 1 depicts the contents identified for preparation of flipped classroom activity.

Table 1. Flipped classroom weekly assessment

\begin{tabular}{|l|l|}
\hline Week & Topic \\
\hline $1-4$ & $\begin{array}{l}\text { 1. Classical Information retrieval models } \\
\text { 2. Retrieval Evaluation }\end{array}$ \\
\hline $5-8$ & $\begin{array}{l}\text { 3. Querying } \\
\text { 4. Structural queries }\end{array}$ \\
& $\begin{array}{l}\text { 5. User Relevance Feedback } \\
\text { 6. Local and Global Analysis }\end{array}$ \\
\hline $9-12$ & $\begin{array}{l}\text { 7. Text operations } \\
\text { 8. Text Compression }\end{array}$ \\
& $\begin{array}{l}\text { 9. Indexing and Searching } \\
\text { 10. Inverted files }\end{array}$ \\
\hline $13-16$ & $\begin{array}{l}\text { 11. Web search } \\
\text { 12. Hyperlink search } \\
\text { 13. Browsing }\end{array}$ \\
\hline
\end{tabular}

The assessment is made in such a way that each of the student is assigned to concentrate on an individual topic with the preparation of flipped classroom activity (Naif et.al. 2013; Nikkie, 2016). The recordings are made using ScreenCAST OMatic tool with recording of about 20 minutes and the same has been published in you tube channel. Some of the students prepared most admirable video lectures and liked by most of the public users in you tube channel. One of the most viewed video as prepared by M.Divya which has got 3662 views and likes for the topic on inverted files corresponding to module 3 . This is one of the successes that we have observed as a part of ALS in engineering education. The same can be found at the following link :

https://www.youtube.com/watch?v=8VjUlLbQ034

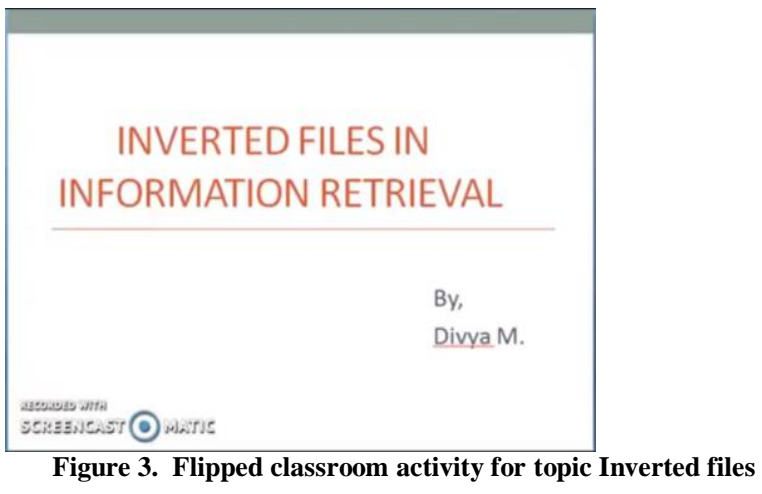

Similarly the monthly assessment is made by using MOOCs online course in any of the online learning platform (Karthikeyan, P, 2018). This will makes the students to have a learning environment which makes them to explore their research ideas and practical applications (Larson et.al., 2020). Here we have used coursera as another platform to make them to disseminate their ideas/views to have practical implementations (Jennifer, 2016). The 2016-20 batch has been provided with these set of ICT learning mechanisms for exploring their learning practice and the attainment of course outcomes (Lekha, 2020; Levine, 2016).

\section{Experimental Results and Evaluation}

Experimental results have been carried out by considering the marks corresponding to interim assignment along with the improvements in internal and its terminal examination marks (Sun et.al., 2020). The ratio given to internal marks was 0.3 and to that of interim assignment is 0.3 and for the terminal examination is 0.4 accordingly. The data is formalized to evaluate the normal distribution in order to identify the statistical relevance. Upper Control Limit (UCL) and Lower Control Limit (LCL) have been set to determine the level of attainments and calculations (Jodi, 2016). The following Table 2 describes about the sample questions and its corresponding blooms level.

Table 2. Sample questions during practice

\begin{tabular}{|l|l|}
\hline Questions & $\begin{array}{l}\text { Blooms } \\
\text { level }\end{array}$ \\
\hline $\begin{array}{l}\text { Recall the process of information retrieval } \\
\text { system. }\end{array}$ & Remember \\
\hline $\begin{array}{l}\text { Explain the roles and responsibilities of database } \\
\text { producers and vendors for online IR systems. }\end{array}$ & Understand \\
\hline $\begin{array}{l}\text { Apply the concept of vector space model and } \\
\text { determine the following cases: }\end{array}$ & Apply \\
1. Construct tf-idf values. \\
2. Given the query "gold silver truck" calculate \\
if-idf vector for the query. \\
3. Construct the score of each document relative \\
to the query. \\
4. Calculate the length of each document and \\
query with accordance to cosSim(d1,q), \\
cosSim(d2,q) and cosSim(d3,q). \\
\hline $\begin{array}{l}\text { Experiment the key expression for ranking } \\
\text { computation in probabilistic model. Provide the } \\
\text { methods for computing the probabilities initially }\end{array}$
\end{tabular}


with its alternatives.

Demonstrate the mechanism for indexing a text Analyze collection in a searching task. Use any of the sample text and built an inverted index. Mention the occurrences point to character positions in the text.

In this course we have 5 course outcomes the measurement is made in such a way that the direct attainment for $\mathrm{CA}$ is $60 \%$ and to that of TE is $30 \%$. The following Table 3describes the attainment values observed for the 2015-19 batch without the applicability of ALS.

Table 3. CO attainment for 2015-19 batch

\begin{tabular}{|l|c|c|c|c|c|}
\hline Course Outcomes & $\begin{array}{c}\text { CO } \\
\mathbf{1}\end{array}$ & $\begin{array}{c}\text { CO } \\
\mathbf{2}\end{array}$ & $\begin{array}{c}\text { CO } \\
\mathbf{3}\end{array}$ & $\begin{array}{c}\text { CO } \\
\mathbf{4}\end{array}$ & $\begin{array}{c}\text { CO } \\
\mathbf{5}\end{array}$ \\
\hline $\begin{array}{l}\text { Direct CO Attainment } \\
\text { (CA) EP 'B' }\end{array}$ & 43 & 1 & 13 & 21 & 12 \\
\hline $\begin{array}{l}\text { Direct CO Attainment } \\
\text { in (CA) }\end{array}$ & 68.2 & 1.5 & 20.6 & 33.3 & 19.0 \\
\hline Normalized (ELA - 60) & 113.7 & 2.6 & 34.3 & 55.5 & 31.7 \\
\hline $\begin{array}{l}\text { Direct CO Attainment } \\
\text { in \% (CA - 0.6 wt) }\end{array}$ & $\mathbf{6 8 . 2 5}$ & $\mathbf{1 . 5}$ & $\mathbf{2 0 . 6}$ & $\mathbf{3 3 . 3}$ & $\mathbf{1 9 . 0}$ \\
\hline $\begin{array}{l}\text { Direct CO Attainment } \\
\text { (TE) }\end{array}$ & 33 & 33 & 33 & 33 & 33 \\
\hline $\begin{array}{l}\text { Direct CO Attainment } \\
\text { in \% (TE) }\end{array}$ & 52.3 & 52.3 & 52.3 & 52.3 & 52.3 \\
\hline Normalized (ELA - 60) & 87.3 & 87.3 & 87.3 & 87.3 & 87.3 \\
\hline $\begin{array}{l}\text { Direct CO Attainment } \\
\text { in \% (TE- 0.3 wt) }\end{array}$ & $\mathbf{3 4 . 9}$ & $\mathbf{3 4 . 9}$ & $\mathbf{3 4 . 9}$ & $\mathbf{3 4 . 9}$ & $\mathbf{3 4 . 9}$ \\
\hline Average Indirect CO in \% & 67 & 55 & 68 & 47 & 45 \\
\hline $\begin{array}{l}\text { Indirect CO Attainment } \\
\text { (0.1 wt) }\end{array}$ & $\mathbf{6 . 7}$ & $\mathbf{5 . 5}$ & $\mathbf{6 . 8}$ & $\mathbf{4 . 7}$ & $\mathbf{4 . 5}$ \\
\hline CO Attainment & $\mathbf{1 0 0}$ & $\mathbf{4 2 . 0}$ & $\mathbf{6 2 . 3}$ & $\mathbf{7 2 . 9}$ & $\mathbf{5 8 . 4}$ \\
\hline
\end{tabular}

In Indirect measurement we have made $10 \%$ which is got through means of feedback (Kim \& Strimel, 2020). The following Table 4 describes the attainment values observed for the 2016-20 batch with the applicability of ALS.

Table 4. CO attainment for 2016-20 batch

\begin{tabular}{|l|l|l|l|l|l|}
\hline Course Outcomes & $\begin{array}{l}\text { CO } \\
\mathbf{1}\end{array}$ & $\begin{array}{l}\text { CO } \\
\mathbf{2}\end{array}$ & $\begin{array}{l}\text { CO } \\
\mathbf{3}\end{array}$ & $\begin{array}{l}\text { CO } \\
\mathbf{4}\end{array}$ & $\begin{array}{l}\text { CO } \\
\mathbf{5}\end{array}$ \\
\hline $\begin{array}{l}\text { Direct CO Attainment } \\
\text { (CA) EP 'B' }\end{array}$ & 43 & 21 & 34 & 39 & 25 \\
\hline $\begin{array}{l}\text { Direct CO Attainment } \\
\text { in \% (CA) }\end{array}$ & 68 & 33 & 53 & 61 & 39 \\
\hline Normalized (ELA - 60) & 113 & 55 & 89 & 103 & 66 \\
\hline $\begin{array}{l}\text { Direct CO Attainment } \\
\text { in \% (CA - 0.6 wt) }\end{array}$ & $\mathbf{6 8}$ & $\mathbf{3 3}$ & $\mathbf{5 3}$ & $\mathbf{6 1}$ & $\mathbf{3 9}$ \\
\hline $\begin{array}{l}\text { Direct CO Attainment } \\
\text { (TE) }\end{array}$ & 43 & 43 & 43 & 43 & 43 \\
\hline $\begin{array}{l}\text { Direct CO Attainment } \\
\text { in \% (TE) }\end{array}$ & 68 & 68 & 68 & 68 & 68 \\
\hline Normalized (ELA - 60) & 113 & 113 & 113 & 113 & 113 \\
\hline $\begin{array}{l}\text { Direct CO Attainment } \\
\text { in \% (TE - 0.3 wt) }\end{array}$ & $\mathbf{4 5}$ & $\mathbf{4 5}$ & $\mathbf{4 5}$ & $\mathbf{4 5}$ & $\mathbf{4 5}$ \\
\hline $\begin{array}{l}\text { Average Indirect CO } \\
\text { in \% }\end{array}$ & 77 & 82 & 96 & 76 & 81 \\
\hline $\begin{array}{l}\text { Indirect CO } \\
\text { Attainment (0.1 wt) }\end{array}$ & $\mathbf{7 . 7}$ & $\mathbf{8}$ & $\mathbf{9 . 6}$ & $\mathbf{7 . 6}$ & $\mathbf{8 . 1}$ \\
\hline
\end{tabular}

\begin{tabular}{|l|l|l|l|l|l|}
\hline CO Attainment & $\mathbf{1 0 0}$ & $\mathbf{8 7}$ & $\mathbf{1 0 0}$ & $\mathbf{1 0 0}$ & $\mathbf{9 3}$ \\
\hline
\end{tabular}

The observed results show that learning based on the proposed method for the student's batch of 2016-20 shown an overall improvement in success ratio with improvements over time complexity measures. Also, the measurement of student's performance against CLO threshold and PLO threshold found to be efficient with statistical evaluation of $P$ value $<0.0001$ (Sheik Abdullah et al., 2018). Hence this effectiveness can be implemented towards all courses semester-wise (Marco et.al. 2015).

Table 5. Descriptive statistics for 2016-20 batch

\begin{tabular}{|l|l|l|l|l|l|}
\hline Statistic & CO1 & CO2 & CO3 & CO4 & CO5 \\
\hline No. of observations & 63 & 63 & 63 & 63 & 63 \\
\hline Minimum & 21.7 & 0.0 & 9.0 & 22.0 & 23.4 \\
\hline Maximum & 100.0 & 51.8 & 95.4 & 96.0 & 82.9 \\
\hline 1st Quartile & 65.2 & 11.1 & 30.3 & 51.5 & 48.9 \\
\hline Median & 80.4 & 18.5 & 42.4 & 69.0 & 56.3 \\
\hline 3rd Quartile & 94.5 & 31.4 & 61.3 & 85.5 & 63.8 \\
\hline Mean & 77.2 & 21.6 & 46.6 & 67.5 & 56.6 \\
\hline Variance (n-1) & $\mathbf{3 9 2 . 8}$ & $\mathbf{1 7 6 . 6}$ & $\mathbf{4 5 6 . 3}$ & $\mathbf{4 7 6 . 2}$ & $\mathbf{1 7 4 . 9}$ \\
\hline $\begin{array}{l}\text { Standard deviation } \\
\text { (n-1) }\end{array}$ & $\mathbf{1 9 . 8}$ & $\mathbf{1 3 . 2}$ & $\mathbf{2 1 . 3}$ & $\mathbf{2 1 . 8}$ & $\mathbf{1 3 . 2}$ \\
\hline
\end{tabular}

Table 6. Descriptive statistics for 2015-19 batch

\begin{tabular}{|l|r|r|r|r|r|}
\hline \multicolumn{1}{|c|}{ Statistic } & $\mathrm{CO} 1$ & $\mathrm{CO} 2$ & $\mathrm{CO} 3$ & $\mathrm{CO} 4$ & $\mathrm{CO} 5$ \\
\hline No. of observations & 65 & 65 & 65 & 65 & 65 \\
\hline Minimum & 21.7 & 0.0 & 9.0 & 22.0 & 23.4 \\
\hline Maximum & 100.0 & 100.0 & 100.0 & 100.0 & 100.0 \\
\hline 1st Quartile & 65.2 & 11.1 & 30.3 & 51.7 & 48.9 \\
\hline Median & 80.4 & 18.5 & 43.1 & 69.5 & 56.3 \\
\hline 3rd Quartile & 95.6 & 33.3 & 63.6 & 86.2 & 64.0 \\
\hline Mean & 77.6 & 22.8 & 47.4 & 68.0 & 57.2 \\
\hline Variance (n-1) & $\mathbf{3 9 4 . 6}$ & $\mathbf{2 6 9 . 8}$ & $\mathbf{4 9 3 . 6}$ & $\mathbf{4 8 5 . 1}$ & $\mathbf{2 0 1 . 6}$ \\
\hline $\begin{array}{l}\text { Standard deviation } \\
\text { (n-1) }\end{array}$ & $\mathbf{1 9 . 8}$ & $\mathbf{1 6 . 4}$ & $\mathbf{2 2 . 2}$ & $\mathbf{2 2 . 0}$ & $\mathbf{1 4 . 1}$ \\
\hline
\end{tabular}

From the results observed with the Table 5 and Table 6 it has been came to notice that the data corresponding to 2015-19 is lower in statistical performance that its preceding batch of students. Hence it has been statistically proved that the performance of the students improved with regard to the incorporation of ALS and its remedial measures. Significant improvisations are also noticed for the batch of 2016-20 batch of students in the computation of variance and SD analysis. Also, from Table 4 for the 2016-20 batch all the Cos has been attained with the Expected Proficiency of level ' $\mathrm{B}$ ' and ALS also been verified accordingly. 


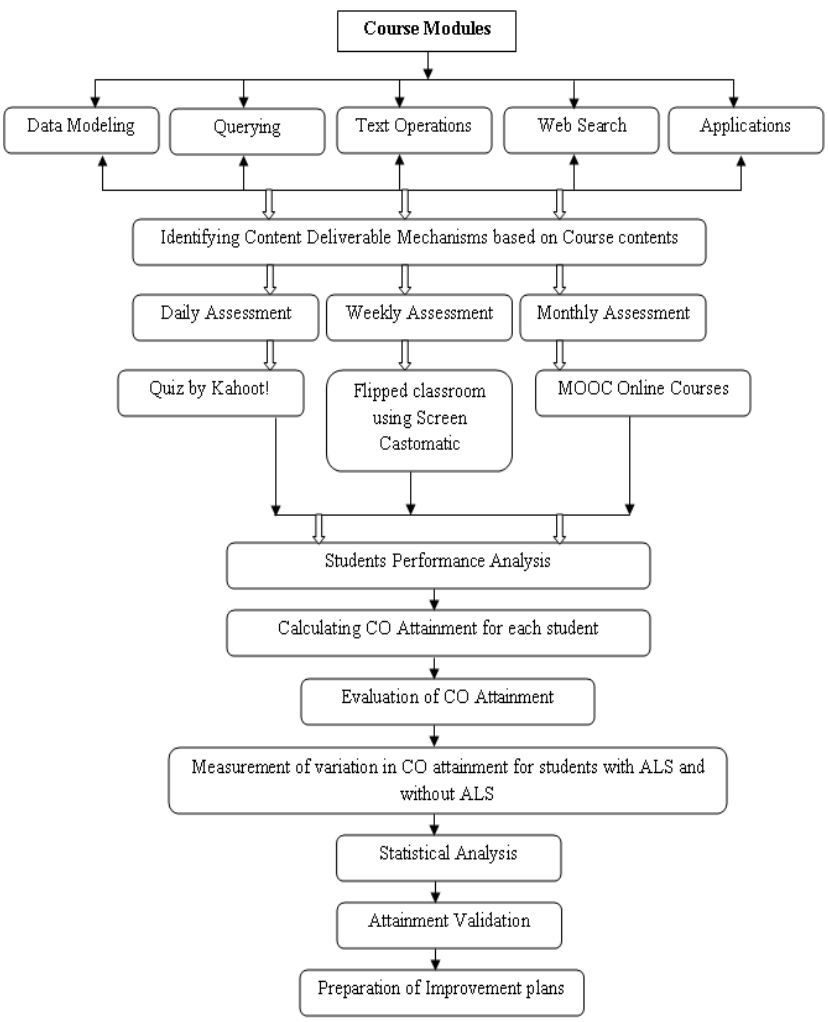

Figure 4 Proposed Methodology

The descriptive statistics has been made for the 2016-20 batch of students the SD values has been found to be nominal with the $\mathrm{CO}$ values and its preferable outcomes (Thayer-Hart, et.al., 2010). The values corresponding to $\mathrm{CO} 2$ has little extent to lower deviations in box plot analysis meanwhile the other COs addressed to the desired extent (William et.al., 2015). The following Table 7 describes the confusion matrix that has been observed as a part of predictive analysis for the 5 COs that has been used for evaluation.

Table 7. Confusion Matrix

\begin{tabular}{|c|c|c|c|c|c|c|}
\hline & $\begin{array}{c}\text { true } \\
\text { Zero }\end{array}$ & $\begin{array}{c}\text { true } \\
\text { One }\end{array}$ & $\begin{array}{c}\text { true } \\
\text { Two }\end{array}$ & $\begin{array}{c}\text { true } \\
\text { Three }\end{array}$ & $\begin{array}{c}\text { true } \\
\text { Four }\end{array}$ & $\begin{array}{c}\text { class } \\
\text { precision }\end{array}$ \\
\hline $\begin{array}{c}\text { pred. } \\
\text { Three }\end{array}$ & 0 & 0 & 0 & 9 & 0 & 100.00 \\
\hline $\begin{array}{c}\text { pred. } \\
\text { Two }\end{array}$ & 0 & 2 & 11 & 0 & 2 & 73.33 \\
\hline $\begin{array}{c}\text { pred. } \\
\text { Zero }\end{array}$ & 15 & 0 & 0 & 0 & 0 & 100.00 \\
\hline pred. One & 0 & 13 & 1 & 3 & 0 & 76.47 \\
\hline $\begin{array}{c}\text { pred. } \\
\text { Four }\end{array}$ & 1 & 0 & 1 & 0 & 5 & 71.43 \\
\hline $\begin{array}{c}\text { class } \\
\text { recall }\end{array}$ & 93.75 & 86.67 & 84.62 & 75.00 & 71.43 & $\mathbf{8 4 . 3 8 \%}$ \\
\hline
\end{tabular}

Research-based analysis of Applications corresponding to information retrieval provided a good impact of adhering research outcomes from the students (Merry, 2017; Miguel et.al, 2020). If this practice is made in a repetitive manner then will be a platform for Outcome Based Education from student-centric to learner-centric strategy in engineering education (Missouri, 2016; Tai, 2019).

\section{Limitations}

The systematic approach that we have adopted has been applied to the course on Information Retrieval (14ITPS0). The success rate depends upon the practice and the way of learning that has been adhered for other courses. Some of the courses will be adaptable to other such ALS techniques and ICT tools that best suits the learning process.

\section{Conclusion and Future Work}

The major challenge in engineering education is to evaluate and examine the students in an efficient way of Teaching-Learning process. The process has to be defined in such a way that it should make the students to explore their knowledge with adaptable practical and thinking skills This research work focus towards the applicability and nonapplicability of ALS strategies in a strategic way with an intention to measure the learning performance of the students for each of the component, with an intention to propose a remedial measure to increase the learning process.

In considering the batch 2015-19, this follows the traditional approach the final level of $\mathrm{CO}$ attainment has been addressed by the $\mathrm{CO} 1$ and $\mathrm{CO} 5$ only. But for the batch 2016-20 the entire COs has been attained with the applicability of ALS in action. We have considered the course on Information Retrieval for the effective implementation of ALS strategies among the student's community. The results proved that research based learning with online MOOC's courses improved the learning process among the students with improved accuracy of about $84.38 \%$ respectively. The statistical measure has also been evaluated with $\mathrm{P}$ value $<0.0001$ accordingly. Hence this will ensure the improvement of performance of learning among the student's by targeting it with a threshold value. Thereby the strength's, pitfalls, of the learning process can be efficiently observed with the proposal of new/changes in the Teaching-Learning process, or the course content. The different capabilities with regard to e-mental health interventions are the future aspects of this proposed scheme. The data corresponding to virtual/online learning is observed for a batch of students in order to measure the effectiveness in learning with regard to the modern technology.

\section{Acknowledgement}

On behalf of our Management we would like to thank our beloved principal, deans, faculty members and students for making us to explore our views in education technology and its practice.

\section{References}

Baker, G.R., Jankowski, N., Provesiz, S. and Kinzie, J. (2012). Using Assessment Results: Promising Practices of Institutions That Do It Well. Urbana, IL: University of Illinois and Indiana University, National Institute for Learning Outcomes Assessment (NILOA). 
Duarte A. J. et al., (2020) "Engineering Education for Sustainable Development: The European Project Semester Approach," in IEEE Transactions on Education, vol. 63, no. 2, pp. 108-117, doi: 10.1109/TE.2019.2926944.

Friess W. A. and Goupee A. J., (2020) "Using Continuous Peer Evaluation in Team-Based Engineering Capstone Projects: A Case Study," in IEEE Transactions on Education, vol. 63, no. 2, pp. 82-87, doi: 10.1109/TE.2020.2970549.

Gloria, \& Oluwadara, (2013) Social Studies Teachers' Intention to use Mobile Phones as a Support and Tutorial Tool for Teaching, IEEE Trans. Society for Information Technology \& Teacher Education International Conference, pp. 3718-3724.

Jennifer E. Roberts, (2016) Collecting and analyzing evidences of student learning at the course level and program level", Norther Virginia Community College, https://www.nvcc.edu/assessment/_docs/FTW7.collectinga naly zingevidstulearning-spr13.pdf.

Jodi Levine Laufgraben, (2016) Using assessment results: setting benchmarks, Faculty Senate Assessment Committee, MSCHE Workshop.

Kim E. and Strimel G. J., (2020) "The Influence of Entrepreneurial Mindsets on Student Design Problem Framing," in IEEE Transactions on Education, vol. 63, no. 2, pp. 126-135, doi: 10.1109/TE.2019.2918253.

Karthikeyan, P, (2018), 'Impacts of Smart Devices in Education', International Journal of Mobile Learning and Organization, Vol. 12, No.2, PP. 97-98.

Larson J., Jordan S. S., Lande M. and Weiner S., (2020) "Supporting Self-Directed Learning in a Project-Based Embedded Systems Design Course," in IEEE Transactions on Education, vol. 63, no. 2, pp. 88-97, doi: 10.1109/TE.2020.2975358.

Lekha Das , \& Megha Sharma (2020) Case Study: Use of MOODLE to Improve Teaching Learning Process in Control System Engineering Vol. 33, No. 3, DOI: $10.16920 /$ jeet/2020/v33i3/144640.

Levine Laufgraben, (2016) Using assessment results: setting benchmarks, Faculty Senate Assessment Committee, MSCHE Workshop.

Marco Arrigo, \& Davide Taibi, (2015) Challenges of using learning analytics techniques to support mobile learning, IEEE Conference on Mobile Learning, pp.147-149.

Merry, R. (2017). Teacher education ICT appropriation model TEAM: A model for ICT appropriation in early childhood initial teacher education. Waikato Journal of Education, 22(4). doi:10.15663/wje.v22i4.593.

Miguel-Revilla, D., Martínez-Ferreira, J. M., \& SánchezAgustí, M. (2020). Assessing the digital competence of educators in social studies: An analysis in initial teacher training using the TPACK-21 model. Australasian Journal of Educational Technology. doi:10.14742/ajet.5281

Missouri (2016) Setting growth targets for students learning objectives: Methods and considerations, Department of Secondary Education, DESE Government.

Naif Radi, \& Hugh C. Davis. (2013) Learning Analytics and Formative Assessment to Provide Immediate Detailed
Feedback Using a Student Centered Mobile Dashboard, IEEE Trans. Mobile Apps, Services and Technologies, pp 262-267.

Nikkie Zanevsky, (2016) Four critical questions to help you set your student learning objectives, https://www.nwea.org/blog/2015/four-critical- questionsto-help-you-set-your-student-learning-objectives/.

Ouafae, E, \& Yasser, EI, \& Lahcen, O, \& Ahmed, D. (2019) A Multiple Linear Regression-Based Approach to Predict Student Performance, Advanced Intelligent Systems for Sustainable Development (AI2SD'2019), pp.9-23.

Ounjit, W. (2011). Learning Theories in Association with Improving University Students' Learning Potential. International Journal for Cross-Disciplinary Subjects in Education, 325-334. doi:10.20533/ijcdse.2042.6364.2011.0046.

Parkavi, R, \& Karthikeyan, P, \& Sheik Abdullah, A. (2018) Impact of Massive Open Online Courses and Best Practices: A Case Study on Social Network Analysis Course, Journal of Engineering Education Transformations, Vol.31,No.3, DOI: 10.16920/jeet/2018/v31i3/120782.

Parkavi, R., Sheik Abdullah, A., Sujitha, S., Karthikeyan, P, (2017), 'Mobile Devices in Class Room', Handbook of Research on Mobile Devices and Smart Gadgets in K-12 Education, IGI Global Book Publishers.

Rhode Island (2016) Setting target in student learning objectives, Department of Education studies, RIDE Website.

Sun, S. Y. H., \& Goodyear, P. (2020). Social coconfiguration in online language learning. Australasian Journal of Educational Technology. doi:10.14742/ajet.5102. Sheik Abdullah, A, Gayathri, N, Abirami, AM Parkavi, R, (2018) A Statistical Approach for setting SLO Targets over Outcome Based Education-A Case Study, Journal of Engineering Education Transformations, DOI: $10.16920 /$ jeet/2018/v0i0/120898

Tai, Y., \& Ting, Y.-L. (2019). English -learning mobile app designing for engineering students' cross-disciplinary learning and collaboration. Australasian Journal of Educational Technology, 120-136. doi:10.14742/ajet.4999.

Thayer-Hart, N., Dykema, J., Elver, K., Schaeffer, N.C., Stevesnson, J. (2010). Survey Fundamentals: A Guide to Designing and Implementing Surveys. University of Wisconsin-Madison, Office of Quality Improvement.

William oakes, maeve Drummond, Carla Zoltowski, (2015), 'EPICS meeting outcomes with Multidisciplinary student teams', Proceedings of the International Conference on Canadian Engineering Education Association (CEEA15), McMaster University. 